\title{
CPAP (Continuous Positive Airway Pressure) is an effective and stable solution for heart sparing radiotherapy of left sided breast cancer
}

Aaron M. Allen", Yasmin Korzets Ceder, Tzippy Shochat, Eyal Fenig, Aron Popovtzer, Dimitry Bragilofsky, Adi Alfassy and Helena Allon

\begin{abstract}
Purpose: Limiting the heart dose in left sided breast cancer radiotherapy is critical. We sought to study the effect of using CPAP (continuous positive airway pressure) as an aid in reducing heart dose in breast cancer radiotherapy.

Methods: Patients with left sided breast cancer receiving adjuvant radiotherapy were enrolled on a prospective IRB (institutional review board) approved clinical trial utilizing CPAP during radiotherapy. Each patient was simulated and planned with and without CPAP and the best dosimetric results determined the patient's treatment. Data on the differences in lung and heart volume and position as well as boost cavity position with and without CPAP were analyzed.

Results: Twenty-four women from 10/16 to 10/18 were enrolled. Seven patients were not treated on study; only two of these were due to treatment issues. Median age was 54 years. $70 \%$ had breast only radiation and $30 \%$ were treated to breast ICW (chest wall) and regional nodes. The median lung volume with CPAP was $60 \%$ larger than without CPAP. (1637 vs. 996 cc) $p<0.001$. The median heart volume decreased 12\% with CPAP. (338 vs. 382 cc) In regards to the DVH, CPAP decreased mean heart dose from 3.02 to 1.6Gy $(p=.0075)$ and V20 of the lungs from 17.1 to 13.8 with CPAP but this was not significant.
\end{abstract}

Conclusion: CPAP assisted radiotherapy was tolerable and produced superior treatment plans in left sided breast cancer. This method is worthy of further investigation as a method to normal tissue sparing treatment of left sided breast cancer patients.

Keywords: Breast Cancer, Radiotherapy, CPAP, Cardiac toxicity

\section{Introduction}

Adjuvant radiotherapy for localized breast cancer is a critical part of the management of the most common malignant disease in women worldwide. It has been shown in multiple studies, that left sided radiotherapy

\footnotetext{
* Correspondence: Ahron.alon@gmail.com

Department of Radiotherapy, Davidoff Center Rabin Medical Center and Sackler Faculty of Medicine Tel Aviv University, 49 Jabotinksi St, 49100 Petach Tikvah, Israel
}

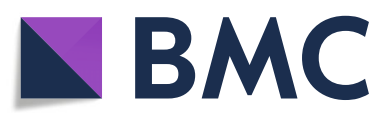

(- The Author(s). 2020 Open Access This article is licensed under a Creative Commons Attribution 4.0 International License, which permits use, sharing, adaptation, distribution and reproduction in any medium or format, as long as you give appropriate credit to the original author(s) and the source, provide a link to the Creative Commons licence, and indicate if changes were made. The images or other third party material in this article are included in the article's Creative Commons licence, unless indicated otherwise in a credit line to the material. If material is not included in the article's Creative Commons licence and your intended use is not permitted by statutory regulation or exceeds the permitted use, you will need to obtain permission directly from the copyright holder. To view a copy of this licence, visit http://creativecommons.org/licenses/by/4.0/. The Creative Commons Public Domain Dedication waiver (http://creativecommons.org/publicdomain/zero/1.0/) applies to the data made available in this article, unless otherwise stated in a credit line to the data.

with suboptimal techniques has led to increased mortality secondary to cardiac events [1].

Multiple studies have been done using techniques to improve the dosimetry of left sided breast radiotherapy. These include two main solutions: improving dosimetry through treatment planning [2,3] (IMRT, proton therapy etc.) or distancing the heart physically through technological advances $[4,5]$ (Automated Breathing Control $\mathrm{ABC}$, Deep inspiration breath hold (DIBH)). The majority 
of centers today utilize a technological advance to spare the heart in left sided breast radiotherapy.

Goldstein et al. published a novel technique to improve thoracic radiotherapy utilizing a well-known technology CPAP (continuous positive airway pressure) to improve thoracic dosimetry [6]. Since CPAP has not been extensively studied in breast cancer we chose to examine its use compared to standard of care tangential radiation without breath hold or other techniques. We therefore designed a prospective clinical trial to examine the impact of CPAP during left sided breast cancer radiotherapy and herein report our findings.

\section{Materials and methods}

From 10/2016 to 10/2018, patients with left sided breast cancer requiring adjuvant radiotherapy were enrolled on a prospective phase II trial with IRB approval. Patients were eligible for enrollment following lumpectomy or mastectomy for localized left breast cancer. Patients receiving intraoperative radiotherapy were excluded.

\section{Study design}

This study was designed as a phase II study with the primary endpoint of reduction in mean heart dose with use of CPAP. With an estimated reduction of $1.0 \mathrm{~Gy}$ and power of $80 \%$ the calculated sample size was 20 patients. Each patient was compared to itself (CPAP vs. No CPAP) which formed the two study groups.

\section{CPAP training}

In order to facilitate the use of daily CPAP assisted radiotherapy patients were trained prior to simulation to wear the CPAP mask and to acclimatize them to positive pressure. Every patient underwent pulmonary function tests and respiratory clearance for CPAP prior to initiation of CPAP. Initial CPAP pressure was chosen at $4 \mathrm{mmHg}$ and gradually elevated per patient comfort to a goal pressure of $15 \mathrm{mmHg}$.

\section{Simulation procedure}

On the day of simulation patients initially underwent CT simulation (GE lightspeed). Patients were placed supine with breast board elevation as standard in our department for breast radiotherapy.

Patients were scanned initially without CPAP both at free breathing (slice thickness $2.5 \mathrm{~mm}$ ) as well as utilizing 4D-CT. 4DCT images were obtained with phase gating and reconstructed on the GE Advantage workstation utilizing 10-phase bins.

Following non-CPAP simulation, patients returned to the clinic and were again fitted with their CPAP mask and gradually increased to the target pressure of 15 mmHg.
CPAP assisted simulation was identical to free breathing simulation including initial helical scan followed by 4DCT images obtained with CPAP.

\section{Radiotherapy planning}

Contouring of CTV nodes or breast boost cavity, as well as normal avoidance structures of lungs and heart was done for all patients. Each patient contours underwent 3D-CRT (three dimensional conformal radiotherapy) planning for adjuvant breast cancer as is standard in our department. Typically this utilized two tangential fields with subfields to improve homogeneity and avoid hot spots as is standard in our department. In cases where axillary nodes were treated a single isocenter technique was used for 3 and 4 field plans. IMRT was not used in this study.

\section{CPAP treatment}

Prior to daily treatment with CPAP patients were prepared for their treatment by undergoing a process of acclimatizing their CPAP pressure to the level that it was set to during simulation. After reaching steady state they were transferred to the linac for therapy with CPAP in place. KV images and MV portal images were used for verification. No additional modifications of normal treatment were necessary with CPAP.

\section{Target coverage}

Both CPAP and non-CPAP plans were created with strict criteria of $95 \%$ of the prescription dose being delivered to 95\% of the breast and nodal (when relevant) PTV.

Normal tissue constraints that were used included:

V $20<35 \%$ (one lung) when nodes were treated and $\mathrm{V} 20<15 \%$ fr breast alone. Heart constraints were focused on mean heart dose with goals of $<4$ Gy with nodal irradiation and $<3$ Gy with breast alone treatment.

Treatment was planned on Eclipse V13.5 (Varian, CA) with a AAA 13.5.35 algorithm.

Following planning on both non-CPAP and CPAP scans the superior plan was chosen for patient treatment.

DVH (dose volume histograms) were calculated for heart and lungs for each patient both with and without CPAP.

\section{DCT analysis}

In addition, to comparing free breathing planning with and without CPAP, we sought to analyze the stability of motion during treatment with and without CPAP. To that end we re-contoured both the heart volume as well as the CTV at the extremes of the breathing cycle at the $50 \%$ (exhale) and $0 \%$ (inhale) states.

These volumes were then analyzed for the $\mathrm{mm}$ of overlap between the CPAP (inhale -exhale) and the nonCPAP (inhale to exhale). 


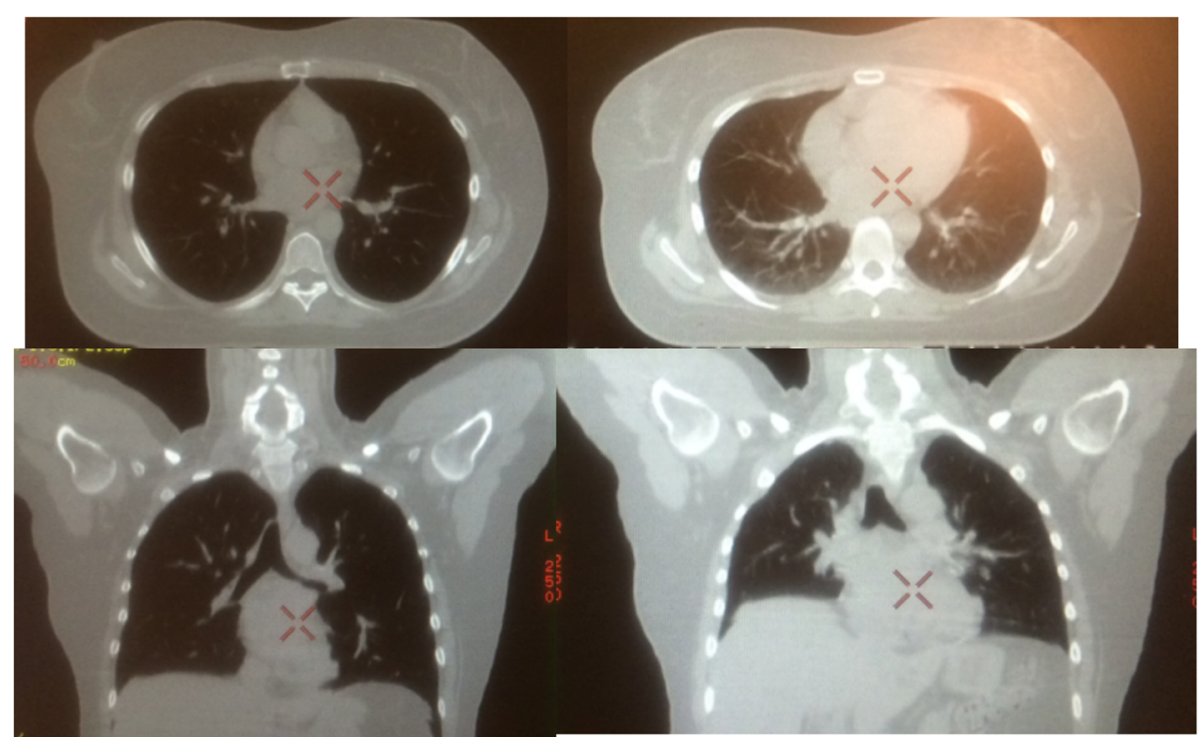

Fig. 1 A comparison of patient on study at simulation. The images on the right are at free breathing axial and coronal. The left hand images are with CPAP at $15 \mathrm{~mm}$ of pressure showing increased lung volume and significant cardiac shrinkage and displacement

\section{Directional heart movement analysis}

In an attempt to analyze the movement of the heart with and without CPAP a vector based on the difference of center of mass was calculated using ECLIPSE (using the Arc Geometry Tool in External Beam Planning). This vector was plotted in a classic three-dimensional coordinate system.

\section{Statistical analysis}

The statistical analysis for this paper was generated using SAS Software, Version 9.4. Continuous variables were presented by Mean \pm Std, Categorical variables were presented by number and percentages. Students' t-test was

Table 1 Comparison of dosimetric data in patients' plans with and without CPAP

\begin{tabular}{llll}
\hline & $\begin{array}{l}\text { With CPAP } \\
\text { Median (SD) }\end{array}$ & $\begin{array}{l}\text { Without CPAP } \\
\text { Median (SD) }\end{array}$ & \\
\hline Lung Volume (cc) & $1506(348)$ & $945(220.5)$ & $\boldsymbol{p}<.0001$ \\
$\begin{array}{l}\text { Mean Lung Dose } \\
\text { (both lungs) }\end{array}$ & 6.68 Gy (5.8) & 6.39 Gy (3.5) & $p=0.42$ \\
Lung V5 & $26.3 \%(11.9)$ & $25.9(16.6)$ & $p=0.87$ \\
Lung V10 & $15.9 \%(9.18)$ & $16.4(14.75)$ & $p=0.41$ \\
Lung V20 & $11.3 \%(7.7)$ & $11.74(13.7)$ & $p=0.22$ \\
Heart Volume (cc) & $351.9(84.97)$ & $352.8(122.6)$ & $p=0.17$ \\
Mean Heart Dose & 1.34 Gy (0.72) & 2.45 Gy (1.9) & $\boldsymbol{p}=. \mathbf{0 0 7 5}$ \\
Heart V2.5Gy & $7.9 \%(10.2)$ & $19.51 \%(12.12)$ & $\boldsymbol{p}=. \mathbf{0 0 2 2}$ \\
Heart V10 & $15.88 \%(9.2)$ & $16.4(14.8)$ & $p=0.41$ \\
\hline
\end{tabular}

SD Standard deviation

$V x$ connoted the volume of the organ receiving " $x$ " dose used to compare univariate variables. Two-sided $p$ values less than 0.05 were considered statistically significant.

\section{Results}

\section{Enrollment}

Twenty-four Patients were enrolled on this prospective phase II trial from October 2016 to October 2018. Three patients withdrew consent prior to treatment. One patient had an unknown latex allergy and had a reaction to the CPAP mask. One patient elected to receive treatment at another center closer to her home. One patient refused radiotherapy. Finally one patient began treatment but was unable to tolerate the CPAP mask. The 17 remaining patients that were enrolled and treated and form the basis of this report.

\section{Patient characteristics}

Of the seventeen patients treated, $50 \%$ were of Caucasian, and $40 \%$ were of Mediterranean descent, 10\% were of Arabic descent. Median age was 54 years. Seventy percent were positive for both estrogen and progesterone receptor status. AJCC TNM stage was Stage I in 50, 25\% Stage II and remainder had DCIS or Stage III.

Table 2 Use of CPAP for Left Breast Radiotherapy

\begin{tabular}{ll}
\hline Pro & Con \\
\hline Decreased heart dose & $\begin{array}{l}\text { Contraindication with } \\
\text { latex allergy }\end{array}$ \\
$\begin{array}{l}\text { Improved stability of tumor } \\
\text { volume }\end{array}$ & $\begin{array}{l}\text { Requires pretreatment } \\
\text { pell tolerated }\end{array}$ \\
Applicable to any clinical \\
setting with minimal cost
\end{tabular}




\section{Treatment characteristics}

Of the seventeen patients $15 \%$ of patients were treated with tangents to breast alone and 55\%of patients were treated to breast plus tumor bed boost. 15\% of patients received radiation to the breast plus regional nodes and $15 \%$ received post-mastectomy radiotherapy to the chest wall and regional nodes.

In the breast only patients the prescription dose was $42.72 \mathrm{~Gy}$ in 16 fractions. In the patients receiving regional nodal irradiation the prescribed dose was 50 Gy in 25 fractions.

\section{Dosimetric details}

The dosimetric details of the CPAP vs. No CPAP can be divided into change in volume of the organ at risk and the planning or DVH differences based on CPAP or no CPAP. The median lung volume with CPAP was $1637 \mathrm{cc}$ (range 1299-2330) compared to 996 cc (range 706-1474 cc) representing a mean difference of $60 \%$ greater lung volume with CPAP $(p<.0001)$. Interestingly the median heart volume with CPAP was $338 \mathrm{cc}$ (range 199-559) as compared to $382 \mathrm{cc}$ (range 232-692) for a decrease of $12 \%$ on average with CPAP but this was not statistically significant. A representative case can be seen in Fig. 1 . In all cases where plans were compared the CPAP plan was superior in all cases and was used for treatment.

In reference to differences in DVH metrics, the most significant difference was mean heart dose. Without CPAP the mean heart dose averaged $3.02 \mathrm{~Gy}$ vs. $1.6 \mathrm{~Gy}$ with CPAP $(p=.0075)$. Of note there were 5 cases where the mean heart dose with standard planning was above 3.5 Gy. In all of these cases CPAP reduced the mean heart dose to under $3 \mathrm{~Gy}$. The ipsilateral V20 was also reduced from an average of $17.1 \%$ without CPAP to $13.8 \%$ with use of CPAP but this was not statistically significant. The complete dosimetric results can be seen in Table 1 .

\section{D CT data}

Differences between the stability due to respiratory motion of the heart were seen between CPAP and no CPAP scans. Without CPAP the median excursion of the heart was 111 cc (range $73-185 \mathrm{cc}$ ). This was compared to a median excursion of $81 \mathrm{cc}$ (range 37-101 cc) with the use of CPAP. The implication is that use of CPAP reduced respiratory excursion and made the location of the structures at risk more stable and consistent with the treatment planning.

\section{Cardiac displacement}

The differences in the cardiac location due to CPAP were analyzed geographically as the motion was unique. The change in the center of mass vectors between the heart with and without CPAP is shown graphically in Fig. 2. The mean vector is also seen and shows a displacement with CPAP consistently caudally and to the right and away from the radiotherapy field.

\section{Discussion}

The use of CPAP is well understood as a therapeutic modality for sleep apnea as well as pediatric pulmonary diseases $[7,8]$. However, until recently it has not been used in the setting of radiotherapy. Goldstein and colleagues published a pioneering study detailing the potential benefits of CPAP in radiotherapy. Their study detailed the benefit of CPAP when added to SBRT for lung lesions. They demonstrated significant differences in decrease of tumor motion as well as the increase of
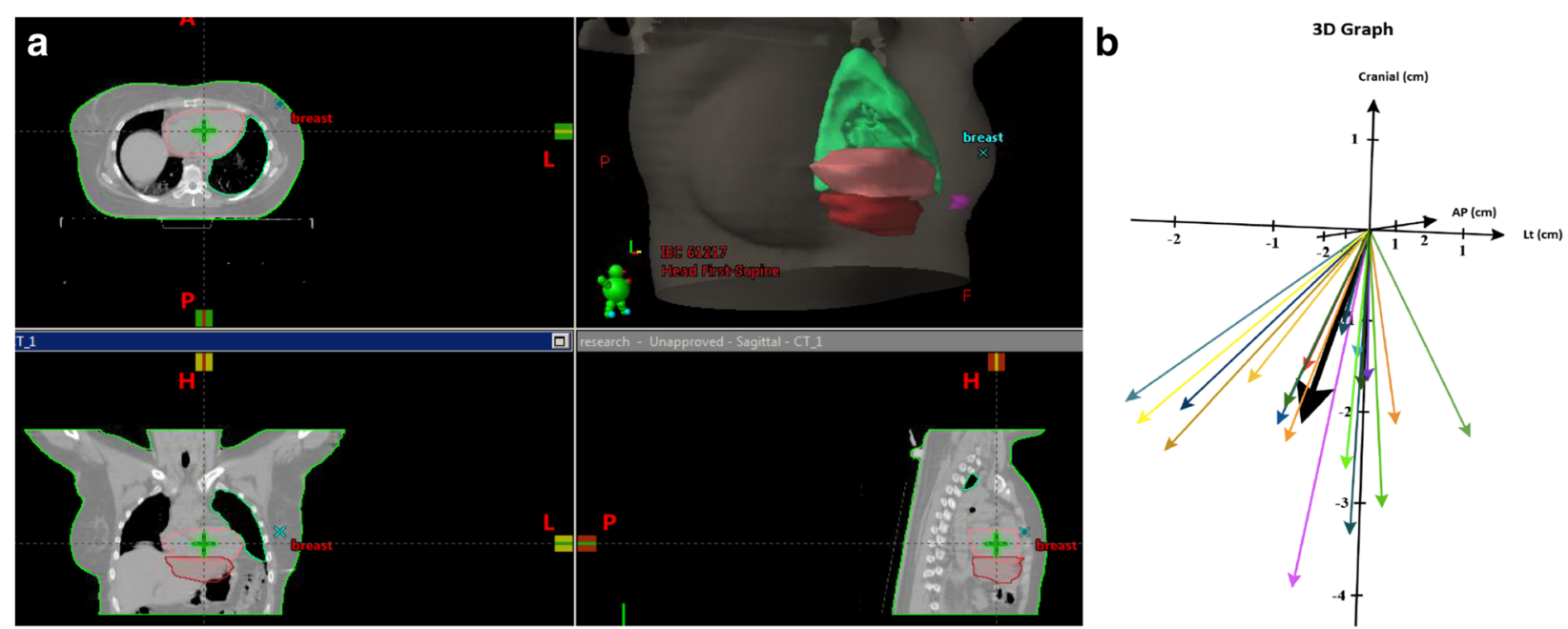

Fig. 2 Heart Motion with CPAP. a depicts the cardiac location with (red) and without (peach) CPAP in one patient. One can see the caudal and inferior displacement. b shows a 3D-plot of the vectors for the change in center of mass of the heart with and without CPAP for each patient on the study. The thick black arrow shows the mean of all the vectors 
total lung volume and decrease in both lung and heart doses [6]. A second group reported a case report of use of CPAP for left breast cancer that was unable to be planned utilizing traditional methods [9].

This small prospective trial is the first effort to our knowledge to describe the effects of CPAP on the radiotherapy of left breast cancer patients. We have shown that CPAP has the ability to significantly decrease the mean heart dose and increase the lung volume. In addition, the use of CPAP produces heart displacement caudally leading to improved dosimetry.

As stated earlier the current standard of care in many centers for left sided breast cancer is DIBH and/or IMRT. How does this standard compare to our study of CPAP?

Improving the geometry of the thorax through manipulating respiration has been very successful at reducing the cardiac dose in breast radiotherapy. The primary method that has been used is deep inspiration breath hold or DIBH. This method utilizes voluntary inflation of the chest to separate the heart from the breast. DIBH has been used and studied in multiple publications and has become a standard of care for left sided breast radiotherapy $[1,5]$. The benefit of DIBH varies throughout the literature but it typically serves to reduce the mean heart dose by $50 \%$ and also significantly reduces the V20 of the ipsilateral lung [10, 11].

In our study we saw $47 \%$ reduction in mean heart dose which is comparable to DIBH studies. However, our reduction in ipsilateral V20 was only $12 \%$ on average, which is lower that what is seen in DIBH. This may be due to the small percentage of patients in our study with nodal irradiation or due to small sample size.

One challenge with DIBH is the reproducibility of the location of both the breast and the normal structures. Most breast plans delivery requires multiple respiratory cycles, which can introduce a critical level of error [12, 13]. In addition, in order to complete the treatment, it requires a cooperative and able patient. This can disqualify older patients or those with limited compliance. Finally, in centers without 4-D CT and or gated linacs this approach is possible but more cumbersome. In our study we found that CPAP improved stability of the breast CTV because it "fixes" the lung in steady state. Although our comparison was to free breathing treatment it would be interesting in future studies to compare DIBH treatment to CPAP based therapy.

One novel aspect of our study, which is unique to CPAP assisted therapy, is the change in size and location of the heart with CPAP. As shown in Fig. 2 the heart typically not only moves away from the breast and chest wall but also is pushed inferiorly. This trajectory has important implications for radiotherapy of breast cancer but also could significantly influence SBRT and other thoracic radiotherapy techniques.
Our study has clear limitations. It is a small single institution trial. There is heterogeneity of patients and plans. This is true of all series of breast cancer plans as one size does not fit all. However, our technique of using each patient as its own control does provide comparable data. In addition, the clinical benefit of this sparing remains unclear as the effects of small doses of radiation on the heart and lung are only seen years after treatment. Nevertheless, this technique shows promise and is certainly worthy of further investigation Table 2 .

\section{Acknowledgements}

The authors would like to thank Jeffery Goldstein for sharing knowledge and assistance in creating this study.

\section{Authors' contributions}

A.M.A was responsible for design and creation of the protocol and was primarily responsible for writing and analyzing of data and creating the manuscript. YKC- was responsible for writing and editing the manuscript. TSwas responsible for statistical analyses and manuscript writing. A.A- was responsible for following patients on study and data collection. H.A. was responsible for analyzing results and creating data charts and detailed dosimetrical analysis. E.F; A.P; D.B- were involved in reviewing the study concepts and analysis of results. All authors were involved and approved of the manuscript.

Funding

Funding for this study was provided by departmental accounts.

Availability of data and materials

The datasets during and/or analyzed during the current study available from the corresponding author on reasonable request.

Ethics approval and consent to participate

This study was approved by the ethics committee (Rabin Medical Center Helsinski committee RMC 0717-15) and all subjects signed informed consent.

\section{Consent for publication}

We have not included any personal data requiring consent.

\section{Competing interests}

The authors declare that they have no competing interests.

Received: 22 October 2019 Accepted: 24 February 2020

Published online: 06 March 2020

\section{References}

1. Yeboa DN, Evans SB. Contemporary breast radiotherapy and cardiac toxicity. Semin Radiat Oncol. 2016;26:71-8.

2. Buwenge M, Cammelli S, Ammendolia I, et al. Intensity modulated radiation therapy for breast cancer: current perspectives. Breast Cancer (Dove Med Press). 2017:9:121-6.

3. Braunstein LZ, Cahlon O. Potential morbidity reduction with proton radiation therapy for breast Cancer. Semin Radiat Oncol. 2018:28:138-49.

4. Eldredge-Hindy $\mathrm{H}$, Lockamy V, Crawford A, et al. Active breathing coordinator reduces radiation dose to the heart and preserves local control in patients with left breast cancer: report of a prospective trial. Pract Radiat Oncol. 2015:5:4-10.

5. Boda-Heggemann J, Knopf AC, Simeonova-Chergou A, et al. Deep inspiration breath hold-based radiation therapy: a clinical review. Int J Radiat Oncol Biol Phys. 2016;94:478-92.

6. Goldstein JD, Lawrence YR, Appel S, et al. Continuous positive airway pressure for motion Management in Stereotactic Body Radiation Therapy to the lung: a controlled pilot study. Int J Radiat Oncol Biol Phys. 2015;93:391-9.

7. Jat KR, Mathew JL. Continuous positive airway pressure (CPAP) for acute bronchiolitis in children. Cochrane Database Syst Rev. 2019;1:CD010473. 
8. Patil SP, Ayappa IA, Caples SM, et al. Treatment of adult obstructive sleep apnea with positive airway pressure: an American Academy of sleep medicine clinical practice guideline. J Clin Sleep Med. 2019;15:335-43.

9. Kil WJ, Pham T, Hossain S, et al. The impact of continuous positive airway pressure on radiation dose to heart and lung during left-sided postmastectomy radiotherapy when deep inspiration breath hold technique is not applicable: a case report. Radiat Oncol J. 2018;36:79-84.

10. Oechsner M, Dusberg M, Borm KJ, et al. Deep inspiration breath-hold for left-sided breast irradiation: analysis of dose-mass histograms and the impact of lung expansion. Radiat Oncol. 2019;14:109.

11. Yeung R, Conroy L, Long K, et al. Cardiac dose reduction with deep inspiration breath hold for left-sided breast cancer radiotherapy patients with and without regional nodal irradiation. Radiat Oncol. 2015:10:200.

12. Fassi A, Ivaldi GB, de Fatis PT, et al. Target position reproducibility in leftbreast irradiation with deep inspiration breath-hold using multiple optical surface control points. J Appl Clin Med Phys. 2018;19:35-43.

13. Koivumaki T, Tujunen J, Viren T, et al. Geometrical uncertainty of heart position in deep-inspiration breath-hold radiotherapy of left-sided breast cancer patients. Acta Oncol. 2017;56:879-83.

\section{Publisher's Note}

Springer Nature remains neutral with regard to jurisdictional claims in published maps and institutional affiliations.

Ready to submit your research? Choose BMC and benefit from:

- fast, convenient online submission

- thorough peer review by experienced researchers in your field

- rapid publication on acceptance

- support for research data, including large and complex data types

- gold Open Access which fosters wider collaboration and increased citations

- maximum visibility for your research: over $100 \mathrm{M}$ website views per year

At BMC, research is always in progress.

Learn more biomedcentral.com/submissions 